\title{
NUEVO GRABADO EN LA OBRA DE PEREYNS
}

\section{Por Santiago Sebastián}

Mi Descubrimiento de un grabado de Marcantonio contribuye a precisar lo que ya señaló la crítica, ${ }^{1}$ es decir, la dependencia del cuadro de Simón Pereyns La Virgen del Perdón de la obra de Rafael la Madonna di Foligno (1511-1512). El grabado de Marcantonio no fue realizado sobre el cuadro del maestro de Urbino, sino sobre un estudio preparatorio, lamentablemente perdido, por tanto se explica que el grabado difiera notablemente del famoso cuadro. ${ }^{2}$

Pereyns no se limitó a copiar literalmente el grabado, sino que cambió aspectos, y se sirvió además, como indicó Angulo, de evocaciones de otra obra rafaelesca, la Virgen de baldaquino de la Pitti. El citado historiador juzgó que las influencias de ambas obras de Rafael quizá le llegaron fundidas, pero nuestro descubrimiento del grabado que damos a conocer pone de manifiesto que no fue así. La fusión de las dos composiciones refaelescas, sin duda, la hizo Pereyns sirviéndose del grabado de Mar. cantonio y de otra fuente todavía no identificada, si es que existió, ya que pudiera ocurrir que se trate sólo de una visión que él recibió en su contacto con los rafaelistas españoles.

Simón Pereyns acusó la influencia del rafaelismo precisamente en su obra más famosa y discutida, la Virgen del Perdón. Pudiera ser que la pieza sea la que se menciona en sus tristes relaciones con la Inquisición. La advocación del Perdón es ficticia, y se llama así por hallarse en el altar de este nombre. No parece ser cierta la información de Fernández del Castillo que creyó haber visto Ia firma de Francisco Zumaya, cuando en realidad la que tiene es Ia de Pereyns. ${ }^{3}$

1 D. Angulo: Historia del Arte Hispanoamericano $\mathrm{In}$, 382. La influencia no italiana la recibió Pereyns de Martín de Vos por medio de los grabados de Jan Sadeler. Angulo: "Pereyns Martín de Vos: El retablo de Huejotzingo", en Anales del Instituto de Arte Americano e Investigaciones Estéticas II, 25-7, México, 1949.

2 O. Fischel: Raphael I, 363 Ed. Kegan Paul. Londres, 1948. Reprodúcese el grabado en Marcantonio and Italian engravers and etchers of the XVI century. Editado por A. H. Hind. New Yord, 1912.

3 M. Toussaint: Pintura colonial en México, 61. Ed. UNAM. México, 1965. Xaviet Moyssén recoge toda la bibliografía sobre Pereyns en la p. 251. 
El hecho de que la crítica de las fuentes se halle en desprestigio, no invalida el que se siga investigando sobre ellas. Evidentemente, la Historia del Arte debe sacar algunas conclusiones de estas dependencias formales, ya que ellas en sí son parte de un problema interesante que apuntan. En este caso la relación concreta con el modelo de un artista tan famoso como Rafael es el mejor argumento que tenemos para demostrar lo imbuido que estaba Pereyns de la estética de su época. Rafael representa la cumbre dei Pleno Renacimiento y fue artista tan admirado porque nadie como él supo interpretar el principio de la imitatio, superando a la misma naturaleza, como los artistas de la antigüedad. ${ }^{4}$ Simón Pereyns, al respetar tan fielmente el modelo del maestro de Urbino no hacía sino subrayar el elevado ambiente humanístico que se respiraba en el Méjico del siglo xvi, y del que tenemos muchas referencias literarias.

Yale University.

4 Para la comprensión de la imitatio yéase R. W. Lees: "Ut pictura poesis: The humanistic theory of painting" en The Art Bulletin, dic., 1940, pp. 197-269.

Nora: Gracias a la Fundación Guggenheim fue posible realizar esta investigación en los fondos de la biblioteca Sterling, en New Haven, Connecticut. 


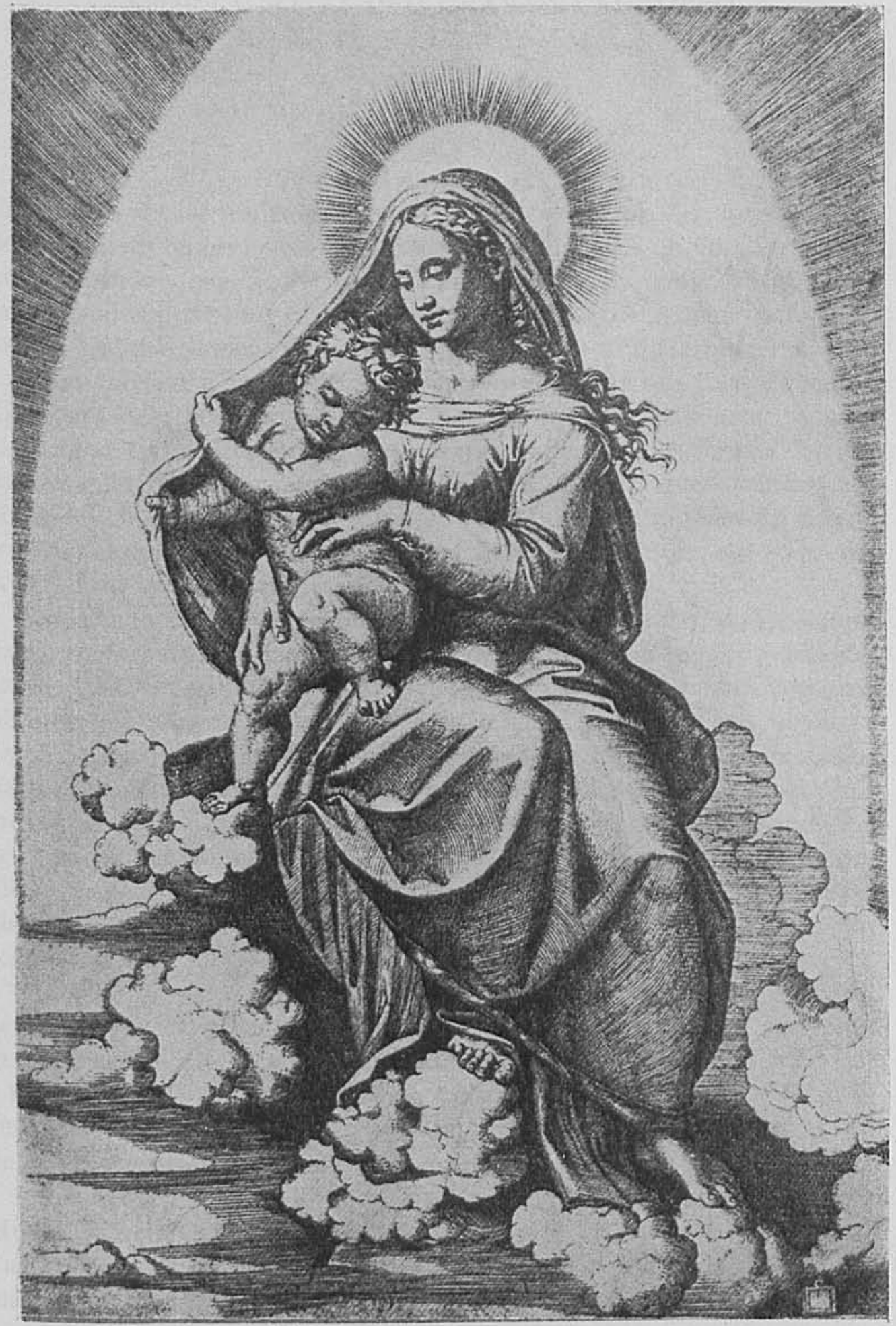

Marcantonio Raimondi "La Virgen y el Niño" según estudio preparatorio de la Madonna di Foligno de Rafael. 